\title{
Synthesis of Amphiphilic Poly(ethylene oxide)- $b$-Poly(methyl methacrylate) Diblock Copolymers via Atom Transfer Radical Polymerization Utilizing Halide Exchange Technique
}

\author{
Xiaoyi Sun, ${ }^{1}$ Hailiang ZHANG, ${ }^{1, \dagger}$ Lingjun ZHANG, ${ }^{1}$ Xiayu WANG, ${ }^{1}$ and Qi-Feng ZHOU ${ }^{2}$ \\ ${ }^{1}$ Institute of Polymer Science, Xiangtan University, Xiangtan 411105, Hunan Province, China \\ ${ }^{2}$ Department of Polymer Science and Engineering, College of Chemistry and Molecular Engineering, \\ Peking University, Beijing 100871, China
}

(Received September 14, 2004; Accepted November 17, 2004; Published February 15, 2005)

\begin{abstract}
Amphiphilic diblock copolymers with different molecular weights and low polydispersities were synthesized by atom transfer radical polymerization (ATRP) of methyl methacrylate (MMA) using PEO-Br as an initiator, which was obtained by the esterification of poly(ethylene oxide) (PEO) with 2-bromoisobutyryl bromide. The polymerization proceeded in solution using halide exchange technique to control ATRP. Fourier transform infrared spectroscopy (FT-IR) and ${ }^{1} \mathrm{H}$ NMR studies confirm the composition of PEO-Br macroinitiator and related diblock copolymers. The results obtained by GPC analysis show that the number average molecular weight was increased versus monomer conversion and the polydispersities were quite low $(<1.10)$, which is the character of a controlled/"living" polymerization. Moreover, the crystallization behavior of PEO- $b$-PMMA block copolymers was studied by means of differential scanning calorimetry (DSC). It was found that the crystallization behavior of the block copolymers exhibited considerable differences in comparison to the neat PEO. The crystallization rate and the degree of crystallinity decreased by an increase of PMMA content. [DOI 10.1295/polymj.37.102]

KEY WORDS Atom Transfer Radical Polymerization / Diblock Copolymer / Poly(ethylene oxide) / Poly(methyl methacrylate) / Halide Exchange /
\end{abstract}

Amphiphilic block copolymers, consisting of a hydrophobic polymer covalently linked to a hydrophilic polymer, have attracted special attention in fundamental and applied research for their unique chain architecture and physical properties. ${ }^{1-5}$ In particular, block copolymers composed of hydrophilic poly(ethylene oxide) (PEO) have been extensively studied, ${ }^{4-6}$ owing to its unique properties such as solubility, crystallinity, flexibility, etc.

Recent developments in controlled/"living" radical polymerization have made it possible to control the polymerization to obtain polymers with predetermined molecular weights, narrow molecular weight distributions, well-defined compositions, architectures, and functionalities. The applicability of controlled/"living" radical polymerization techniques in the synthesis of block polymers is well documented in the literature of those that use the nitroxide-mediated radical polymerization (NMRP), ${ }^{7,8}$ atom transfer radical polymerization (ATRP) $)^{9,10}$ and reversible additionfragmentation chain transfer (RAFT) polymerization. ${ }^{11}$ Among them, ATRP is a convenient method for the preparation of block copolymers where a transition metal compound acts as a carrier of a halogen atom in a reversible redox process.

Recently, Kops et al. ${ }^{12,13}$ reported the synthesis of block copolymers containing PEO and PS by ATRP using a PEO macroinitiator obtained by functionalizing the HO-PEO-OH with 2-bromopropionyl or 2chloropropionyl ester end group. The polymerization proceeded in a living manner to yield well-defined block copolymers, which are difficult to synthesize by the sequential anionic method. Thus, esterification of a hydroxyl group of a preformed macromolecule with halogenated acyl halide proved to be an excellent method for producing macroinitiators suitable for ATRP. ${ }^{13,14}$ With this approach, a number of block copolymers were synthesized from PEO macroinitiator. ${ }^{4,15-23}$ For example, Höcker and coworkers ${ }^{4,16}$ prepared poly(ethylene oxide)- $b$-poly(hydroxyethyl methacrylate) (PEO- $b$-PHEMA) and PEO- $b$-PS block copolymers. Lim et al. ${ }^{17}$ reported the synthesis of block copolymers comprising PEO and poly(fluorooctyl methacrylates). The ATRP of MMA in the synthesis of triblock copolymers from a difunctional PEO macroinitiator was also reported. ${ }^{20}$ Moreover, Chen et $a .^{21-23}$ reported the synthesis of poly(ethylene oxide)- $b$-poly(3-(trimethoxysilyl) propyl methacrylate) (PEO- $b$-PTMSPMA) diblock copolymers by ATRP using $\mathrm{PEO}-\mathrm{Br}$ as a macroinitiator, and prepared soluble nanocapsules through self-assembly of these block copolymers. In these works, the block co-

${ }^{\dagger}$ To whom correspondence should be addressed (E-mail: hailiangzhang@xtu.edu.cn). 


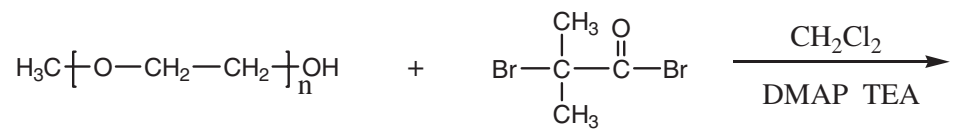

$$
\begin{aligned}
& \mathrm{H}_{3} \mathrm{C}+\mathrm{O}-\mathrm{CH}_{2}-\mathrm{CH}_{2}+\underset{\mathrm{n}}{\mathrm{O}-\mathrm{C}}-\stackrel{\mathrm{O}}{\stackrel{\mathrm{O}}{\mathrm{C}}-\underset{\mathrm{l}}{\mathrm{C}}-\mathrm{Br}} \underset{\mathrm{CH}_{3}}{\stackrel{\mathrm{C} \mathrm{H}_{3}}{\mathrm{CuX} / \text { bipy } 50^{\circ} \mathrm{C}}}
\end{aligned}
$$

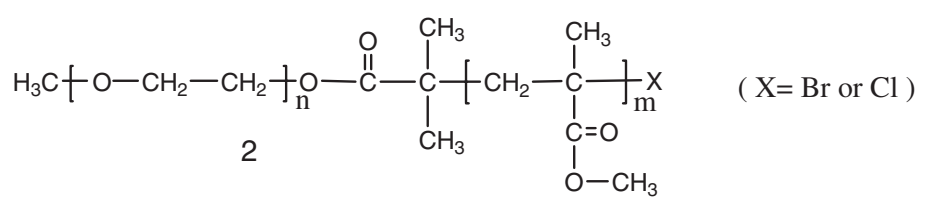

Scheme 1. Synthetic route of PEO- $b$-PMMA diblock copolymer.

polymers were prepared by ATRP using $\mathrm{PEO}-\mathrm{Br}$ / $\mathrm{CuBr}$ or $\mathrm{PEO}-\mathrm{Cl} / \mathrm{CuCl}$ initiator/catalyst system. However, the mixed halogen system $\mathrm{PEO}-\mathrm{Br} / \mathrm{CuCl}$ has hardly been used in the synthesis of block copolymers, which is expected to improve the molecular weight distribution of the resulting polymer.

In this paper we describe how well-defined PEO- $b$ PMMA diblock copolymers with low polydispersities may be synthesized by the ATRP route using halide exchange technique. The synthesis is outlined in Scheme 1 and first a monofunctional hydrophilic 2bromo isobutyrate PEO macroinitiator (1) is synthesized, which is subsequently used in the preparation of diblock copolymers PEO- $b$-PMMA (2) by being heated with methyl methacrylate in solution under ATRP conditions. The structures and molecular characteristics of the PEO- $b$-PMMA diblock copolymers were studied by GPC, FT-IR and ${ }^{1} \mathrm{H}$ NMR. The crystallization behavior of the copolymers was investigated using differential scanning calorimetry (DSC).

\section{EXPERIMENTAL}

\section{Materials}

2-Bromoisobutyryl bromide (98\%, Alfa) was freshly distilled by room temperature under vacuum. Triethylamine (TEA) was refluxed with $p$-toluenesulfon$\mathrm{yl}$ chloride and then distilled. The resulting amine free TEA was stored over $\mathrm{CaH}_{2}$. Before use, it was refluxed and distilled again. 4-(Dimethylamino)pyridine (DMAP) was recrystallized from toluene. Methylene dichloride $\left(\mathrm{CH}_{2} \mathrm{Cl}_{2}\right)$ was shaken with portions of concentrated $\mathrm{H}_{2} \mathrm{SO}_{4}$ until the acid layer remained colorless, then washed with water, aqueous $5 \% \mathrm{NaHCO}_{3}$ and with water again, and finally distilled from $\mathrm{CaH}_{2}$. PEO $\left(M_{\mathrm{n}}=5000\right.$, Alfa $)$ was dried by azeotropic distillation with toluene before use. Traces of residual toluene were removed under vacuum. Chlorobenzene (99\%, Acros) was washed with concentrated sulphuric acid to remove thiophenes, followed by washed twice with water, once with 5\% sodium carbonate solution, and again with water before dried with anhydrous calcium chloride and distilled. $\mathrm{CuCl}$ was prepared from $\mathrm{CuCl}_{2} \cdot 2 \mathrm{H}_{2} \mathrm{O}$, then stirred in glacial acetic acid and washed with methanol, and then dried in vacuum. Methyl methacrylate (MMA) was passed through a column with activated $\mathrm{Al}_{2} \mathrm{O}_{3}$ (120-160 mesh) to remove the inhibitor, stored over $\mathrm{CaH}_{2}$, and then vacuum distilled before polymerization. All other reagents ( $p$-toluenesulfonyl chloride ( $p$-TSCl), tetrahydrofuran (THF), 2,2'-bipyridine (bipy), ether, ethanol, toluene) were purchased from commercial sources and used as received without purification.

\section{Preparation of $\mathrm{PEO}-\mathrm{Br}$ Macroinitiator}

A $0.915 \mathrm{~g}$ (7.5 mmol) sample of DMAP in $20 \mathrm{~mL}$ of dry methylene dichloride was mixed with $0.505 \mathrm{~g}$ $(5.0 \mathrm{mmol})$ of TEA. The solution was transferred into a $250 \mathrm{~mL}$ three-neck round-bottom flask equipped with condenser, dropping funnel, gas inlet/outlet, and a magnetic stirrer. After cooling to $0{ }^{\circ} \mathrm{C}, 2.875 \mathrm{~g}$ (12.5 mmol) of 2-bromoisobutyryl bromide in $20 \mathrm{~mL}$ of $\mathrm{CH}_{2} \mathrm{Cl}_{2}$ was added. To the formed yellow dispersion was added $25 \mathrm{~g}(5 \mathrm{mmol})$ of PEO in $100 \mathrm{~mL}$ of dry $\mathrm{CH}_{2} \mathrm{Cl}_{2}$ dropwise during $1 \mathrm{~h}$ under dry nitrogen; subsequently the temperature was allowed to rise to room temperature. The reaction was continued under stirring for $18 \mathrm{~h}$. The solution was filtered, half of the solvent was evaporated, and the PEO-Br macroinitiator was precipitated in cold diethyl ether. After dissolution in absolute ethanol, the solution was stored overnight to recrystallize the product. The macroinitiator was filtered, washed with cold diethyl ether, and dried in vacuum.

\section{ATRP of MMA Using PEO-Br Macroinitiator}

PEO- $b$-PMMA diblock copolymers were synthesized by solution polymerization in chlorobenzene. In a typical run, a glass tube was charged with $0.25 \mathrm{~g}(0.05 \mathrm{mmol})$ of PEO-Br macroinitiator, $0.50 \mathrm{~g}$ 
(5 mmol) of MMA, $0.0050 \mathrm{~g}(0.05 \mathrm{mmol})$ of $\mathrm{CuCl}$ or $0.0072 \mathrm{~g}(0.05 \mathrm{mmol})$ of $\mathrm{CuBr}, 0.0234 \mathrm{~g}(0.15 \mathrm{mmol})$ of bipy and $1.125 \mathrm{~g}$ of chlorobenzene. After degassed with three freeze-pump-thaw cycles, the tube was sealed under vacuum and then immersed in a thermostated oil bath at $50^{\circ} \mathrm{C}$. At a certain time, the tube was withdrawn and cooled to room temperature. The reaction mixture was diluted with THF. After passing the solution through a column with activated $\mathrm{Al}_{2} \mathrm{O}_{3}$ to remove the catalyst, and precipitating into ether, PEO- $b$ PMMA diblock copolymer was obtained and dried in a vacuum oven overnight at room temperature.

\section{Characterization}

The yield of the polymerization was determined gravimetrically. FT-IR spectra of the macroinitiator and block copolymers were recorded on a PerkinElmer Spectrum One Fourier Transform Infrared Spectrometer using the $\mathrm{KBr}$ pellet technique. The number average molecular weights $M_{\mathrm{n}}$ and polydispersity $M_{\mathrm{w}} / M_{\mathrm{n}}$ were measured with a Waters 1515 gel permeation chromatograph equipped with three Styragel columns $\left(10^{3}, 10^{4}\right.$ and $\left.10^{5} \AA\right)$ using THF as an eluent (1.0 $\mathrm{mL} \mathrm{min}^{-1}$ ) at $30^{\circ} \mathrm{C}$. The column system was calibrated by a set of monodisperse polystyrene standards. ${ }^{1} \mathrm{H}$ NMR spectra were obtained at $25^{\circ} \mathrm{C}$ on a Bruker AV400 NMR spectrometer (400 MHz) using $\mathrm{CDCl}_{3}$ as solvent and tetramethylsilane (TMS) as the internal reference. Thermal analysis was performed using a TA instruments Q10 differential scanning calorimeter equipped with a RCS accessory under nitrogen atmosphere. Heating and cooling rates were $10^{\circ} \mathrm{C} \mathrm{min}^{-1}$. The recorded temperatures were calibrated using Indium as standard.

\section{RESULTS AND DISCUSSION}

\section{Synthesis and Characterization}

In the first step of the synthesis of PEO- $b$-PMMA diblock copolymers (Scheme 1), PEO-Br macroinitiator was synthesized by reacting PEO with 2-bromoisobutyryl bromide according to the literature. ${ }^{12}$ The reaction was carried out at $0{ }^{\circ} \mathrm{C}$ in $\mathrm{CH}_{2} \mathrm{Cl}_{2}$ in the presence of TEA and DMAP in order to avoid cleavage of the polymer chains as found in case of other derivatizations of $\mathrm{PEO} .^{24}$

$\mathrm{CuBr}$ or $\mathrm{CuCl}$, complexed with bipy, was used respectively to catalyze atom transfer radical polymerization of MMA with PEO-Br macroinitiator in this work. The reaction was carried out in chlorobenzene solution at $50^{\circ} \mathrm{C}$. The molar ratio of MMA, PEO$\mathrm{Br}, \mathrm{CuBr}$ or $\mathrm{CuCl}$, bipy was 100:1:1:3.

Figure 1 shows the GPC curves of PEO-Br macroinitiator and some of the PEO- $b$-PMMA diblock copolymers synthesized by using $\mathrm{PEO}-\mathrm{Br}$ as an initiator

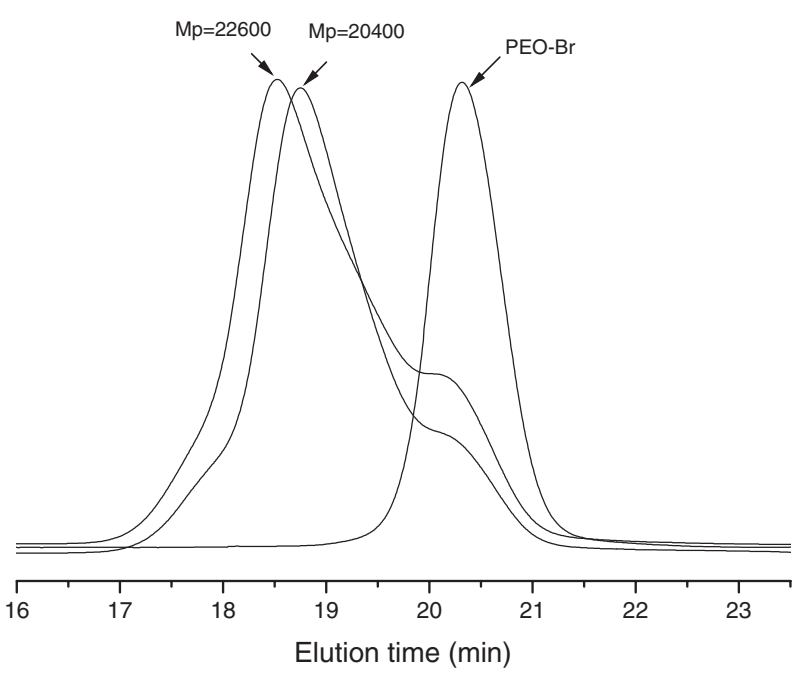

Figure 1. GPC traces of PEO-Br and related PEO- $b$-PMMA diblock copolymers catalized by $\mathrm{CuBr} /$ bipy.

and $\mathrm{CuBr}$ /bipy complex as a catalyst under ATRP condition. As observed, the resulting block copolymers displayed bimodal elution peaks with a still remaining unreacted $\mathrm{PEO}-\mathrm{Br}$ part. It implied that the $\mathrm{PEO}-\mathrm{Br} / \mathrm{CuBr}$ initiation/catalyst system gave essentially uncontrolled polymerization, which was attributed to its inefficient initiation.

Matyjaszewski et al. ${ }^{25,26}$ reported utilizing halide exchange to improve control of ATRP. They found that the mixed halogen system $\mathrm{R}-\mathrm{Br} / \mathrm{CuCl}$ would give faster initiation, slower propagation, and therefore better control of molecular weight and polydispersity. To avoid the above inefficient initiation phenomenon, we are preferable to carry out the reaction using a $\mathrm{PEO}-\mathrm{Br} / \mathrm{CuCl}$ mixed halogen system.

Figure 2 reveals the GPC curves of PEO- $b$-PMMA diblock copolymers synthesized by using $\mathrm{PEO}-\mathrm{Br}$ as an initiator and $\mathrm{CuCl} /$ bipy complex as a catalyst in chlorobenzene solution. After the chain extension reaction, an increase in molecular weight from $M_{\mathrm{n}}=9800 \mathrm{~g} \mathrm{~mol}^{-1}, M_{\mathrm{w}} / M_{\mathrm{n}}=1.02$ to $M_{\mathrm{n}}=19700$ $\mathrm{g} \mathrm{mol}^{-1}, M_{\mathrm{w}} / M_{\mathrm{n}}=1.10$ was achieved. The resulting copolymers displayed unimodal elution peaks, and moreover, there is no tail on the low molecular weight, i.e., no remaining $\mathrm{PEO}-\mathrm{Br}$ macroinitiator even at low MMA conversion. All the GPC curves of diblock copolymers are narrow and symmetrical. The results approved that the $\mathrm{PEO}-\mathrm{Br} / \mathrm{CuCl}$ initiator/catalyst system should give better control of polymerization than $\mathrm{PEO}-\mathrm{Br} / \mathrm{CuBr}$ system.

In this work, PEO $5000\left(M_{\mathrm{n}, \mathrm{NMR}}=5300 \mathrm{~g} \mathrm{~mol}^{-1}\right)$ was chosen to prepare amphiphilic block copolymer via ATRP using halide exchange technique, and the PEO- $b$-PMMA diblock copolymers were obtained without purification. Comparison with other research groups using $\mathrm{PEO}-\mathrm{Cl} / \mathrm{CuBr}$ or $\mathrm{PEO}-\mathrm{Cl} / \mathrm{CuCl}$ system 


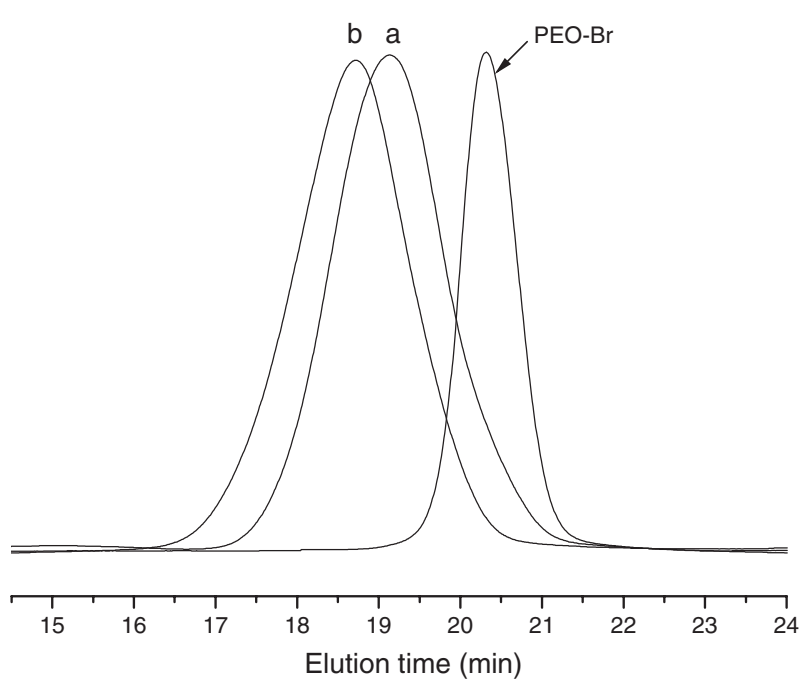

Figure 2. GPC traces of PEO-Br and related PEO- $b$-PMMA diblock copolymers catalized by $\mathrm{CuCl}$ /bipy: (a) PEO- $b$-PMMA4, (b) PEO- $b$-PMMA-5.

to prepare amphiphilic block copolymers, ${ }^{15,20}$ PEO$\mathrm{Br}$ and $\mathrm{CuCl} /$ bipy system used in our study should give better control of molecular weight and polydispersity. The results agree with Matyjaszewski et al.'s finding ${ }^{25,26}$ and confirm that halide exchange could improve control of ATRP.

The PEO, PEO-Br macroinitiator and the obtained PEO- $b$-PMMA diblock copolymers were analyzed by using IR spectroscopy. Representative FT-IR spectra of PEO, PEO-Br and diblock copolymer PEO- $b$ PMMA-4 are shown in Figure 3. After acetylation reaction, a carbonyl stretch occurs at $1734 \mathrm{~cm}^{-1}$ correspondingly in the spectrum of PEO-Br macroinitiator. All of the characteristic absorptions for PEO and PMMA segments appear in the spectrum of the diblock copolymer (Figure 3c). The spectrum of block copolymer also exhibits $1734 \mathrm{~cm}^{-1}$ absorption peak, assigned to the carbonyl absorption, which is much stronger than that of the macroinitiator. The ether stretch occurs at $1109 \mathrm{~cm}^{-1}$ for the copolymer and PEO precursor. The bands at 963 and $843 \mathrm{~cm}^{-1}$ are the characteristic of the crystalline phase of PEO. ${ }^{27}$ The two peaks appear in the spectrum of the copolymer, and their intensities are associated with the content of PEO block and its crystallinity. The results agree well with those from DSC, which will be discussed in the following section.

The chemical structures of PEO, PEO-Br and the obtained PEO- $b$-PMMA diblock copolymers were characterized by a $400 \mathrm{MHz}{ }^{1} \mathrm{H}$ NMR spectroscopy. In the ${ }^{1} \mathrm{H}$ NMR spectrum of PEO (Figure 4a), the $-\mathrm{CH}_{2}-\mathrm{CH}_{2}-\mathrm{O}-$ resonance is observed at $3.65 \mathrm{ppm}$. Figure $4 \mathrm{~b}$ shows the typical ${ }^{1} \mathrm{H}$ NMR spectrum of the resulting $\mathrm{PEO}-\mathrm{Br}$ macroinitiator. The complete substitution of the hydroxyl group of PEO in $\mathrm{CDCl}_{3}$

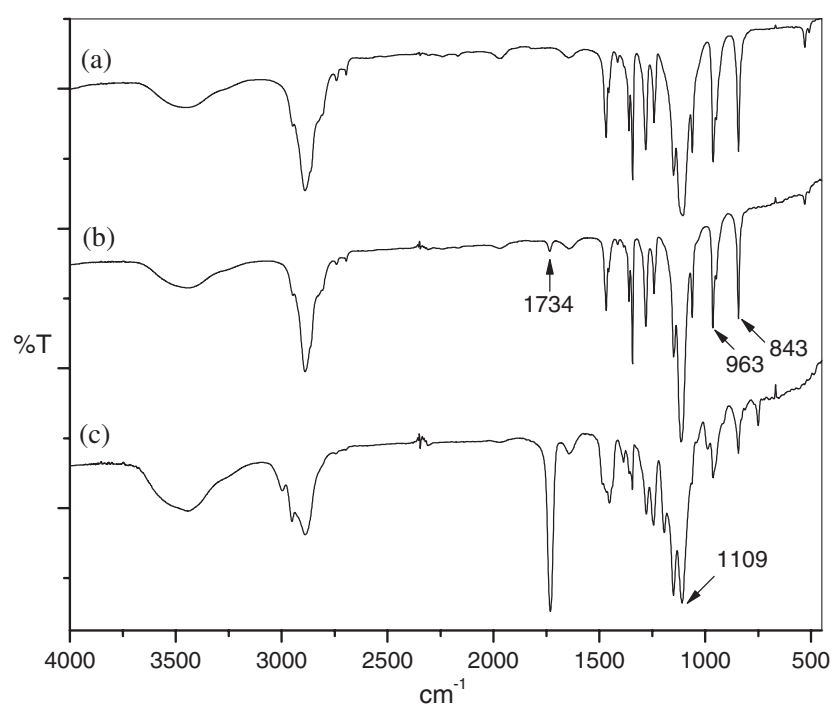

Figure 3. FT-IR spectra of (a) PEO, (b) PEO-Br and (c) diblock copolymer PEO- $b$-PMMA-4.

around $2.45 \mathrm{ppm}$ disappeared after the esterification and two new signals appeared at 4.33 and $1.94 \mathrm{ppm}$ due to the substituted PEO. The peak area ratio of $a, b$ and $d$ is $6: 2: 3$, which also confirmed the complete esterification. Thus the obtained PEO-Br macroinitiator is functionalized with $\omega$ - $\alpha$-bromoisobutyryl group. By comparison of the integral ratio of signals (a) and (c), molecular weight of PEO-Br was estimated to be $5500 \mathrm{~g} \mathrm{~mol}^{-1}$, differently to the value 9800 $\mathrm{g} \mathrm{mol}^{-1}$ measured by GPC (GPC results: PEO-Br: $\left.M_{\mathrm{n}}=9800 \mathrm{~g} \mathrm{~mol}^{-1}, M_{\mathrm{w}} / M_{\mathrm{n}}=1.02\right)$. This discrepancy may attribute to its hydrodynamic behavior in THF solution. The molecular weight of PEO-Br macroinitiator is a little bigger than the molecular weight of PEO estimated by ${ }^{1} \mathrm{H}$ NMR $\left(M_{\mathrm{n}}=5300 \mathrm{~g} \mathrm{~mol}^{-1}\right)$, which show no cleavage of the polymer chains occurred during the esterification as reported in the literature. $^{28}$

${ }^{1} \mathrm{H}$ NMR spectrum of diblock copolymer PEO- $b$ PMMA-4 (Figure $4 \mathrm{c}$ ) shows the $-\mathrm{CH}_{2}-\mathrm{CH}_{2}-\mathrm{O}$ resonance of $\mathrm{PEO}$ at $3.65 \mathrm{ppm}$ and the $\mathrm{O}-\mathrm{CH}_{3}$ protons of PMMA at $3.60 \mathrm{ppm}$. In Figure $4 \mathrm{c}$, the signals (e, $\mathrm{f}$ and $\mathrm{g}$ ) at $0.8-1.2,1.7-2.0,3.60 \mathrm{ppm}$ are ascribed to the repeated MMA units. Characteristic resonance of $-\mathrm{CH}_{2}-\mathrm{CH}_{2}-$ bond (signal (c)) in PEO units is also present in the ${ }^{1} \mathrm{H}$ NMR spectrum of the copolymer. These data illustrate the presence of both PEO and MMA blocks in the polymer chain.

The composition of the diblock copolymers was determined by means of ${ }^{1} \mathrm{H}$ NMR spectroscopy from the integral ratio of the signals originated from the PMMA block at $0.85,1.02$, and $1.21 \mathrm{ppm}$ (signal (e), $3 \mathrm{H}, \mathrm{CH}_{3}$ ) and from the PEO and MMA region (3.4-3.8 ppm) (signal (c), $4 \mathrm{H},-\mathrm{CH}_{2}-\mathrm{CH}_{2}-$, signal (g), $3 \mathrm{H}, \mathrm{O}-\mathrm{CH}_{3}$ ) according to the following equation: 


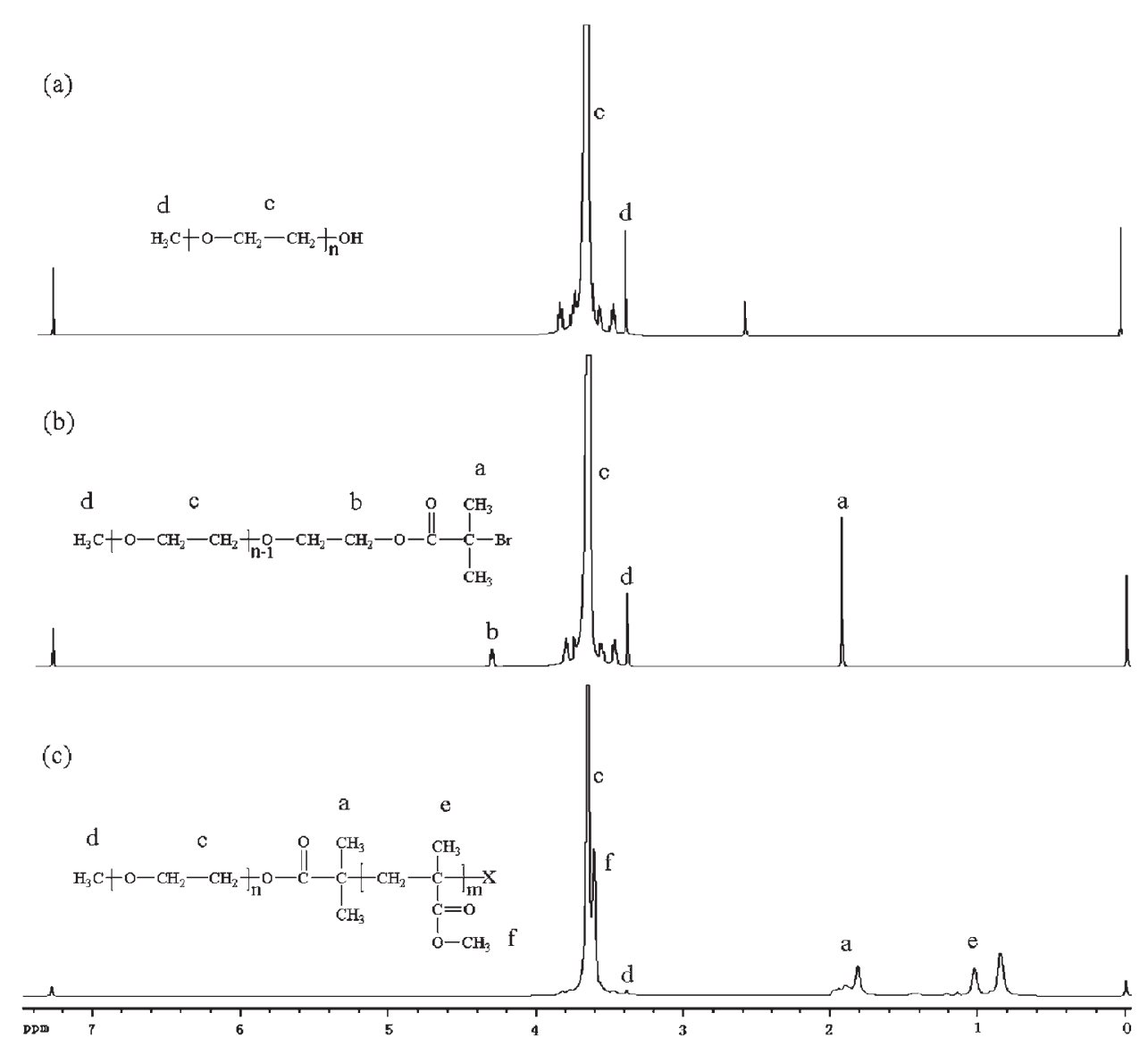

Figure 4. ${ }^{1} \mathrm{H}$ NMR spectra of (a) PEO, (b) PEO-Br, and (c) PEO- $b$-PMMA-4.

$f_{\text {MMA }}=\left(I_{\mathrm{e}} \times 100 / 3\right) /\left[I_{\mathrm{e}} \times 100 / 3+\left(I_{\mathrm{c}+\mathrm{g}}-I_{\mathrm{e}}\right) \times 44 / 4\right]$

Where $I_{\mathrm{e}}$ and $I_{\mathrm{c}+\mathrm{g}}$ are the integral of the signals originated from the PMMA block at $0.8-1.2 \mathrm{ppm}$ and the PMMA and PEO block at 3.4-3.8 ppm; 100 and 44 are the molar masses of MMA and $-\mathrm{CH}_{2}-\mathrm{CH}_{2}-\mathrm{O}$ repeat unit in PEO segment respectively.

Calculated from $f_{\mathrm{MMA}}$ and $M_{\mathrm{n}}$ estimated by NMR analysis of PEO-Br, we can obtain the number average molecular weights of the corresponding PEO- $b$ PMMA diblock copolymers. The results are summarized in Table I.

\section{Thermal Analysis}

PEO is a semicrystalline polymer and its properties are related to its morphological features such as degree of crystallization, size (thickness and lateral dimension of lamellae) and perfection of crystallites. Therefore, it is important to study the crystallization behavior of amphiphilic block copolymer consisting of PEO as hydrophilic and crystallizable segment.

In order to understand the link between PMMA block and crystallization of PEO, the crystallization behavior of PEO- $b$-PMMA copolymers was investigated by means of DSC. The following protocol was used for each sample: heating from -60 to $140^{\circ} \mathrm{C}$
Table I. GPC, NMR data of PEO, PEO-Br, and PEO- $b$ PMMA $^{\text {a }}$ diblock copolymers

\begin{tabular}{lccccc}
\hline \multicolumn{1}{c}{ Samples } & $\begin{array}{c}\text { Yield } \\
(\%)\end{array}$ & $\begin{array}{c}M_{\mathrm{n}, \mathrm{GPC}} \\
\left(\times 10^{-4}\right)\end{array}$ & $\begin{array}{c}M_{\mathrm{w}} / M_{\mathrm{n}} \\
(\mathrm{GPC})\end{array}$ & $\begin{array}{c}M_{\mathrm{NMR}} \\
\left(\times 10^{-4}\right)\end{array}$ & $\begin{array}{c}f_{\mathrm{MMA}} \\
(\mathrm{NMR})\end{array}$ \\
\hline PEO & & 0.89 & 1.02 & 0.53 & \\
PEO-Br & & 0.98 & 1.02 & 0.55 & \\
PEO- $b$-PMMA-1 & 41.8 & 1.15 & 1.05 & 0.67 & 18 \\
PEO- $b$-PMMA-2 & 50.6 & 1.23 & 1.07 & 0.80 & 31 \\
PEO- $b$-PMMA-3 & 60.0 & 1.36 & 1.09 & 0.95 & 42 \\
PEO- $b$-PMMA-4 & 69.7 & 1.62 & 1.10 & 1.10 & 50 \\
PEO- $b$-PMMA-5 & 90.1 & 1.97 & 1.10 & 1.41 & 61 \\
\hline
\end{tabular}

${ }^{a}$ ATRP of MMA initiated by PEO-Br macroinitiator in chlorobenzene solution Condition: $[\mathrm{MMA}]_{0} /[\mathrm{PEO}-\mathrm{Br}]_{0} /$ $\left[\mathrm{CuCl}(\text { bipy })_{3}\right]_{0}=100: 1: 1,50^{\circ} \mathrm{C}$.

and kept at this temperature for $1 \mathrm{~min}$, then cooling from 140 to $-60^{\circ} \mathrm{C}$, and finally reheating from -60 to $140{ }^{\circ} \mathrm{C}$. Both the heating and cooling rate are $10^{\circ} \mathrm{Cmin}^{-1}$. Figures 5-7 exhibit DSC scans of PEO, PEO-Br macroinitiator and related PEO- $b$ PMMA block copolymers with different PMMA contents ((1) $18 \mathrm{wt} \%$, (2) $31 \mathrm{wt} \%$, (3) $42 \mathrm{wt} \%$, (4) $50 \mathrm{wt} \%$ and (5) $61 \mathrm{wt} \%$ ). PEO blocks in all diblock copolymers have lower melting enthalpy and lower crystallinity as compared with those of pure PEO precursors. Table II lists the thermal data for each of the 


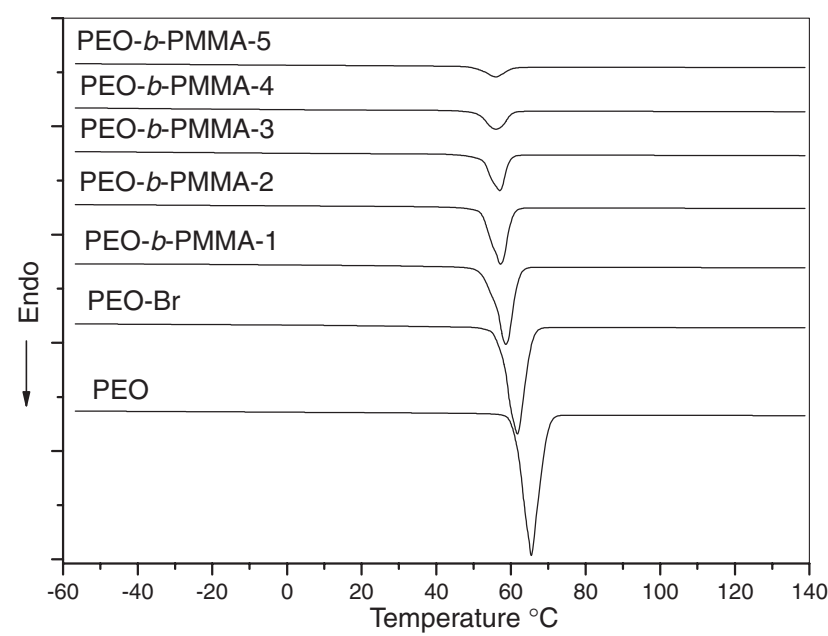

Figure 5. DSC first heating curves of PEO, PEO-Br, and PEO- $b$-PMMA diblock copolymers.

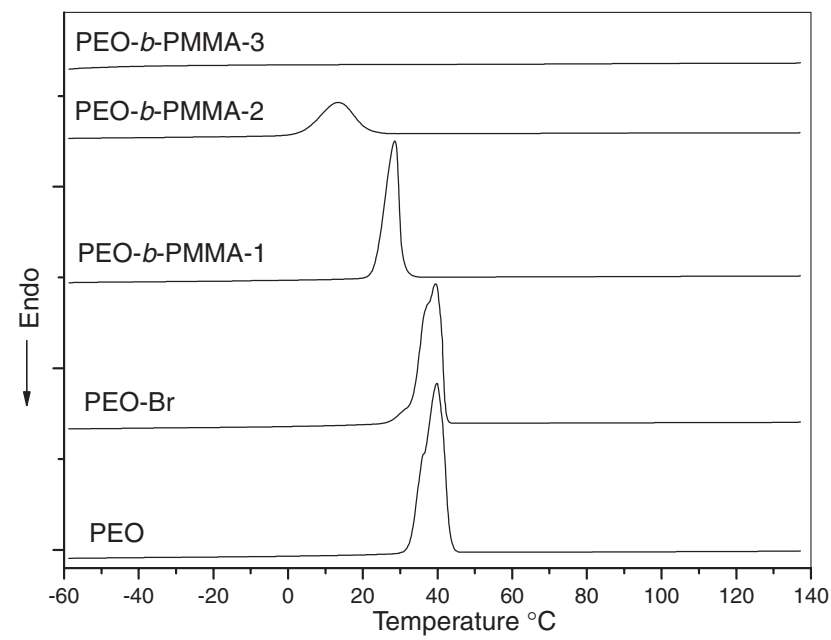

Figure 6. DSC first cooling curves of PEO, PEO-Br, and PEO- $b$-PMMA diblock copolymers.

samples shown in Figures 5-7. The data in Table II exhibit a systematic trend of degree of crystallinity $\left(X_{\mathrm{c}}\right)$ depression with increasing PMMA content. The degree of crystallinity of the sample was determined by measuring the enthalpic change at melt.

Figures 5 and 7 show that for the samples from both solution crystallization and melt crystallization, the melting transition temperature $\left(T_{\mathrm{m}}\right)$ and the melting enthalpy $\left(\Delta H_{\mathrm{m}}\right)$ of PEO block decreased with the increase of PMMA content, which indicated that their non-isothermal crystallization rate decreased with increasing PMMA content. Just from crystallization temperature $\left(T_{\mathrm{c}}\right)$ recorded from the cooling scans of the samples (Figure 6), a general tendency about the crystallization rate of copolymers can be seen. Crystallization temperature $\left(T_{\mathrm{c}}\right)$ of PEO- $b$-PMMA copolymers from the melt crystallization decreased with increasing PMMA content. Samples 3, 4, and 5

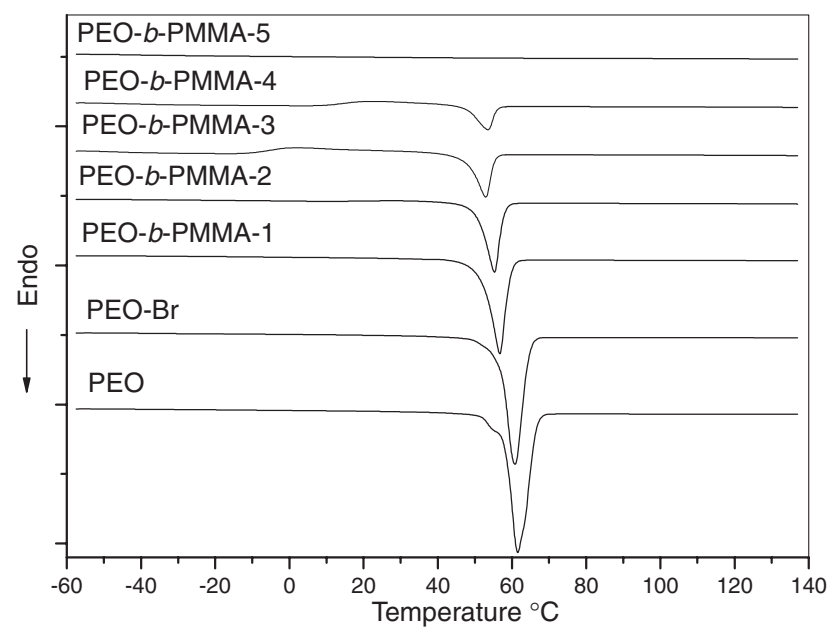

Figure 7. DSC second heating curves of PEO, PEO-Br, and PEO- $b$-PMMA diblock copolymers.

Table II. Summary of DSC results for PEO, PEO-Br, and copolymers

\begin{tabular}{lllllr}
\hline \multicolumn{1}{c}{ Samples } & \multicolumn{1}{c}{$\begin{array}{c}T_{\mathrm{m}}{ }^{\mathrm{a}} \\
\left({ }^{\circ} \mathrm{C}\right)\end{array}$} & $\begin{array}{c}\Delta H_{\mathrm{m}}{ }^{\mathrm{a}} \\
\left(\mathrm{Jg}^{-1}\right)\end{array}$ & $\begin{array}{l}X_{\mathrm{c}}{ }^{\mathrm{b}} \\
(\%)\end{array}$ & $\begin{array}{c}T_{\mathrm{c}}{ }^{\mathrm{c}} \\
\left({ }^{\circ} \mathrm{C}\right)\end{array}$ & $\begin{array}{r}\Delta H_{\mathrm{c}}{ }^{\mathrm{c}} \\
\left(\mathrm{Jg}^{-1}\right)\end{array}$ \\
\hline PEO & $65.4 / 61.6$ & $199.9 / 178.5$ & 87.9 & 39.9 & 176.7 \\
PEO-Br & $61.8 / 60.8$ & $164.0 / 151.4$ & 74.6 & 39.5 & 150.2 \\
PEO- $b$-PMMA-1 & $58.7 / 56.7$ & $118.2 / 108.6$ & 53.5 & 28.6 & 103.8 \\
PEO- $b$-PMMA-2 & $57.2 / 55.3$ & $82.0 / 72.2$ & 35.6 & 13.3 & 58.3 \\
PEO- $b$-PMMA-3 & $57.0 / 52.9$ & $50.2 / 48.7$ & 24.0 & & \\
PEO- $b$-PMMA-4 & $56.0 / 53.5$ & $32.1 / 28.3$ & 13.9 & & \\
PEO- $b$-PMMA-5 & $55.9 /$ & $17.5 /$ & & & \\
\hline
\end{tabular}

${ }^{\text {a }}$ The melting temperature $\left(T_{\mathrm{m}}\right)$ and melting enthalpy of the sample are determined from the DSC first and second heating scans, respectively. ${ }^{\mathrm{b}}$ The crystallinity of the sample, $X_{\mathrm{c}}$, is determined by the equation: $X_{\mathrm{c}}=\left(\Delta H_{\mathrm{m}} / \Delta H_{\mathrm{m}}^{0}\right) \times 100$, where $\Delta H_{\mathrm{m}}$ is the melting enthalpy of the sample from the second DSC heating scans and $\Delta H_{\mathrm{m}}^{0}$ is the melting enthalpy of $100 \%$ crystalline PEO $\left(\Delta H_{\mathrm{m}}^{0}=203 \mathrm{~J} \mathrm{~g}^{-1}\right) .{ }^{29}{ }^{\mathrm{c}}$ The crystallization temperature $\left(T_{\mathrm{c}}\right)$ and crystallization enthalpy of the sample are determined from the DSC cooling scans.

(PMMA content: 42, 50, and $61 \mathrm{wt} \%$ ) do not exhibit the exothermic peak characteristic of crystallization from the melting PEO phase. But an exothermic peak observed for samples 3 and 4 (respectively at 1.2 and $20.9^{\circ} \mathrm{C}$ ) was attributed to cool crystallization from the amorphous phase during the second heating scan (Figure 7). There is no peak in the second heating scan curve of PEO- $b$-PMMA-5, which imply that the sample could not crystallize from the melting phase when PMMA content reached $61 \mathrm{wt} \%$. The above indicate that the PEO present in the sample exhibits difficulty to crystallize with the increasing PMMA content during the cooling scan.

The study indicates that the crystallization behavior of PEO is affected by PMMA segment. The crystallization rate and the degree of crystallinity of PEO de- 
creased with the PMMA content increased. No glass transition was found in DSC study. In fact it is very difficult to see the glass transition of the PMMA block in the DSC heating curve because of melting of the PEO block.

\section{CONCLUSIONS}

Amphiphilic diblock copolymers with low polydispersities were successfully synthesized by atom transfer radical polymerization of methyl methacrylate in chlorobenzene solution using $\mathrm{PEO}-\mathrm{Br}$ as an initiator and $\mathrm{CuCl} /$ bipy complex as a catalyst. FT-IR and ${ }^{1} \mathrm{H}$ NMR spectra confirmed the block architecture of the copolymers. The results obtained by GPC analysis indicate that the number average molecular weight was increased versus monomer conversion and the polydispersities were quite low $(<1.10)$, which is the character of a controlled/"living" polymerization. Moreover, it is found that crystallization behavior of the block copolymer exhibited considerable differences in comparison to the neat PEO. The crystallization rate and the degree of crystallinity decrease by the increase of PMMA content. In addition, the melting point $\left(T_{\mathrm{m}}\right)$ and melting enthalpy $\left(\Delta H_{\mathrm{m}}\right)$ of the PEO- $b$-PMMA samples were much lower as compared with those of pure PEO precursors.

Acknowledgment. This work is financially supported by the National Nature Science Foundation of China under contrast 20374042.

\section{REFERENCES}

1. M. Minoda, M. Sawamoto, and T. Higashimura, Macromolecules, 25, 2796 (1992).

2. S. Forster and M. Antonietti, Adv. Mater., 10, 195 (1998).

3. A. Fischer, A. Brembilla, and P. Lochon, Polymer, 42, 1441 (2001).

4. B. Reining, H. Keul, and H. Höcker, Polymer, 43, 7145 (2002).

5. P. Alexandridis and J. F. Holzwarth, Langmuir, 13, 6074 (1997).
6. B. Svensson and U. Olsson, Macromolecules, 33, 7413 (2000).

7. M. K. Georges, P. R. N. Vergin, P. M. Kazmaier, and G. K. Harmer, Macromolecules, 26, 2987 (1993).

8. T. Diaz, A. Fischer, A. Jonquieres, A. Brembilla, and P. Lochon, Macromolecules, 36, 2235 (2003).

9. J. S. Wang and K. Matyjaszewski, J. Am. Chem. Soc., 117, 5614 (1995).

10. J. Ueda, M. Matsuyama, M. Kamigaito, and M. Sawamoto, Macromolecules, 31, 557 (1998).

11. C. Tang, T. Kowalewski, and K. Matyjaszewski, Macromolecules, 36, 8587 (2003).

12. K. Jankova, X. Chen, J. Kops, and W. Batsberg, Macromolecules, 31, 538 (1998).

13. K. Jankova, J. H. Truelsen, X. Chen, J. Kops, and W. Batsberg, Polym. Bull., 42, 153 (1999).

14. H. Kim, L. Bes, D. M. Haddleton, and E. Khoshdel, J. Polym. Sci., Polym. Chem. Ed., 39, 1833 (2001).

15. B. Reining, H. Keul, and H. Höcker, Polymer, 40, 3555 (1999).

16. B. Reining, H. Keul, and H. Höcker, Polymer, 43, 3139 (2002).

17. K. T. Lim, M. Y. Lee, M. J. Moon, G. D. Lee, S. S. Hong, J. L. Dickson, and K. P. Johnston, Polymer, 43, 7043 (2002).

18. S. Liu, J. V. M. Weaver, Y. Tang, N. C. Billingham, and S. P. Armes, Macromolecules, 35, 6121 (2002).

19. Y. Ma, Y. Tang, N. C. Billingham, and S. P. Armes, Macromolecules, 36, 3475 (2003).

20. R. Krishnan and K. S. V. Srinivasan, Eur. Polym. J., 39, 205 (2003).

21. J. Du, Y. Chen, Y. Zhang, C. C. Han, K. Fischer, and M. Schmidt, J. Am. Chem. Soc., 125, 14710 (2003).

22. J. Du and Y. Chen, Macromolecules, 37, 5710 (2004).

23. J. Du and Y. Chen, Macromolecules, 37, 6322 (2004).

24. J. M. Harris, J. Macromol. Sci., Part C: Rev. Macromol. Chem. Phys., 25, 325 (1985).

25. K. Matyjaszewski, J. L. Wang, T. Grimaud, and D. A. Shipp, Macromolecules, 31, 1527 (1998).

26. K. Matyjaszewski, D. A. Shipp, J. L. Wang, T. Grimaud, and T. E. Patten, Macromolecules, 31, 6836 (1998).

27. F. E. Bailey and J. V. Koleske, "Poly(ethylene oxide)," Academic Press, New York, N.Y., 1976.

28. M. Lee, D. W. Lee, B. K. Cho, J. Y. Yoon, and W. C. Zin, J. Am. Chem. Soc., 120, 13258 (1998).

29. B. Wuderlich, "Macromolecular Physics, Vol. 3," Academic Press, New York, N.Y., 1980. 